\title{
Experimental Investigation and Performance Simulation of Kit Horizontal Axis Wind Turbine
}

\author{
Mustafa M. M. Alaskari \\ Department of Energy Engineering \\ University of Baghdad
}

\begin{abstract}
The present study explores the performance of the small horizontal axis wind turbine. NACA-44 profile for wind Education Kit at different wind velocity range of (3.5 to 5.5 $\mathrm{m} / \mathrm{s}$ ) is used to achieve this study. The effects of changing the pitch angles $\left(10^{\circ}, 30^{\circ}\right.$, and $\left.45^{\circ}\right)$ of the blade on the power performance of small wind turbine rotor models were investigated experimentally. (3, 4 and 6 blades) have been used to compare the results at each pitch angle for the different wind velocity. A computer program code was built to simulate the mathematical model. The axial induction factor indicates the degree to which the wind velocity at the upstream of the rotor is slowed down by the turbine; the power coefficient and the thrust coefficient for a range of axial induction factor have been evaluated and compared for different blades pitch angles. The maximum power coefficient obtained is about 0.51 occurs at $10^{\circ}$ pitch angle for the 3 blades. Furthermore, it has been shown that the increase of wind velocity at a certain point will drop the overall efficiency down.
\end{abstract}

\section{Keywords}

Small horizontal axis wind turbine, axial induction factor, simulates the performance, pitch angles, power coefficient.

\section{INTRODUCTION}

In order to ensure the stable operation of wind turbines using non-grid-connected wind power, as well as the efficient utilization of wind resources, a study of condition monitoring of wind turbines is necessary. A test system of wind turbines under laboratory conditions based on a Lab View platform has been designed [1]. In order to extract the maximum possible power, it is important that the blades of small wind turbines start rotating at the lowest possible wind speed [2]. Large Scale Wind Turbines have been extensively examined for decades but only a few studies have been conducted on the small-scale wind turbines especially for low wind speed applications, the wind tunnel experiments revealed that SWEPT has rated power output of $1 \mathrm{~W}$ and is capable of producing power output up to $2.2 \mathrm{~W}$ at wind speed of $5.5 \mathrm{~m} / \mathrm{s}$ [3].

Ali M. Rasham et al., [4] investigated experimentally the performance for a small horizontal portable wind turbine (SHPWT) of different blades profiles under laboratory conditions at different wind velocity range of $(3.7-5.8 \mathrm{~m} / \mathrm{s})$.

The possibility of increasing the efficiency of the small horizontal axis wind turbine rotor by adding winglets at the tip of the blade was presented. The effects of changing the winglet configuration with the blade on the power performance of small wind turbine rotor models were investigated experimentally [5].
Nitin Tenguria et al., [6] evaluated the performance of horizontal axis wind turbine blades based on optimal rotor theory, a method for the determination of the aerodynamic performance characteristics using NACA airfoils is given for three bladed horizontal axis wind turbine. Ozcan Atlam [7] used a small scale education experiment kit with wind generator-PEM electrolyzer system and modeling, performance characteristics of the wind system are defined for different wind speeds. Three different horizontal axis wind turbine (HAWT) blade geometries with the same diameter of $0.72 \mathrm{~m}$ using the same NACA4418 airfoil profile have been investigated both experimentally and numerically [8].

A developed methodology is used to predict the optimal performance of the horizontal axis wind turbine in terms of the most critical parameters such as tip speed ratio, pitch angle, blade number and wind speed. Interesting generalized performance maps were conducted. Results show that low pitch is recommended for low wind speed regime [9].

The performance of a horizontal axis wind turbine continuously operating at its maximum power coefficient was evaluated by a calculation code based on Blade Element Momentum (BEM) theory. The mathematical code produced a power co-efficiency curve which showed that notwithstanding further increases in rotational velocity a constant maximum power value was reached even as wind velocity increased [10].

\section{EXPERIMENTAL WORK}

In this experimental work, Wind Education Kit with NACA44 blade profile is used. Figure (1) shows the general aspect of the experimental setup. The kit horizontal wind turbine extracts the kinetic energy stored in the wind and converted it into electrical energy. Three cases in the present work were used to make a comparison between the power coefficient, thrust coefficient, output power, and overall efficiency of three, four and blades for different pitch angles $\left(10^{\circ}, 30^{\circ}\right.$, and $45^{\circ}$ ) and different wind velocity. The fan is placed in line with the wind turbine as an appropriate wind source range of (3.5 to $5.5 \mathrm{~m} / \mathrm{s}$ ) to exert wind toward the wind turbine device in order to spin the blades of the kit horizontal wind turbine to produces power. Spark sensor is used to measure a voltage and current produced after the rotation of wind turbine blades. A digital anemometer is used to measure the wind velocity at the upwind region of the wind turbine. Also, it was used to measure the wind velocity ahead of the blades of the wind turbine.

\section{MATHEMATICAL MODEL}

The kinetic energy of an air mass (m) moving at a velocity (v) can be expressed as:

$\mathrm{K} . \mathrm{E}=\frac{1}{2} \mathrm{mv}^{2}$ 
The power $\mathrm{P}$ that the wind contains is calculated by differentiating the energy with respect to time. For a constant wind speed $\mathrm{v}$ the power is:

$\mathrm{P}=\frac{1}{2} \dot{\mathrm{m}} \mathrm{v}_{1}^{2}$

The air mass flow rare with density $(\rho)$ flows through an area (A) with speed $\left(v_{1}\right)$ is:

$\mathrm{m}^{\prime}=\rho A v_{1}$

The power of the wind becomes:

$\mathrm{P}_{\mathrm{w}}=\frac{1}{2} \rho \mathrm{v}_{1}{ }^{3} \mathrm{~A}$

The axial induction factor which is the functional reduction of the wind velocity at the rotor calculated as:

$\mathrm{a}=\frac{\mathrm{v}_{1}-\mathrm{v}_{\mathrm{r}}}{\mathrm{v}_{1}}$

The power coefficient $\mathrm{C}_{\mathrm{p}}$ and is given by:

$\mathrm{C}_{\mathrm{p}}=4 \mathrm{a}(1-\mathrm{a})^{2}$

The thrust coefficient $\mathrm{C}_{\mathrm{T}}$ of a wind is defined as:

$\mathrm{C}_{\mathrm{T}}=4 \mathrm{a}(1-\mathrm{a})$

The electrical output power can be estimated from the output voltage and current experimentally calculated which can be written as:

$\mathrm{P}_{\mathrm{e}}=\mathrm{VI}$

The ratio of electrical power $\mathrm{P}_{\mathrm{e}}$ of the turbine to the power of the wind $\mathrm{P}_{\mathrm{w}}$ defines the efficiency for the power utilization of the wind:

$\eta=\frac{P_{e}}{P_{w}}$

\section{RESULTS AND DISCUSSION}

In order to study horizontal axis wind turbine performance, a laboratory kit wind turbine has been used. It has been investigated under different wind velocity range of (3.5 to 5.5 $\mathrm{m} / \mathrm{s}$ ) and checking the effect of changing the blades pitch angles and the number of blades for each angle. The representation of power coefficient and thrust coefficient with axial induction factor for a different number of blades is shown in figure (2, 3 and 4) respectively. It has been experimentally observed that changing the pitch angle has sufficient effect on measuring and calculated coefficients, $C_{p}$, and $\mathrm{C}_{\mathrm{T}}$ of three blades were better than the case of (4 and 6) blades. Also, it has been shown that $\mathrm{C}_{\mathrm{p}}$ and $\mathrm{C}_{\mathrm{T}}$ record better results for $10^{\circ}$ pitch angle of $(3$ and 4$)$ blades, while there was no significant difference of the determined coefficients in the case of 6 blades wind turbine.

Figure (5, 6 and 7) shows the evolution of the wind power and the overall generated power of the wind turbine for different wind speeds range ( 3.5 to $5.5 \mathrm{~m} / \mathrm{s})$. The measurements were compared for (3, 4 and 6 blades), each case was tested to three different pitch angle $\left(10^{\circ}, 30^{\circ}\right.$, and $\left.45^{\circ}\right)$. The wind power for all cases was the same since there is no change in the upwind speed range. It can be seen that $P_{w}$ is always greater than $P_{e}$, because of the reduction of the rotor speed. A maximum power of $4.1 \mathrm{~W}$ at a wind speed of $5.5 \mathrm{~m} / \mathrm{s}$ was obtained for the four blade wind turbine at $10^{\circ}$ pitch angle.

The overall efficiency behavior by the changing influence of blades number and blade pitch angles is illustrated in figure $(8,9$ and 10) respectively. The Maximum efficiency achieved was $70.97 \%$ at $10^{\circ}$ pitch angle of 3 blade wind turbine. It can be shown that the overall efficiency of 3 and 4 bladed rotors is better than the use of 6 bladed rotors. As it can be seen from the figures, the efficiency distributions show little changes after the upwind speed of $5 \mathrm{~m} / \mathrm{s}$ for each of the cases. It is evident that efficiencies at the speed of $4 \mathrm{~m} / \mathrm{s}, 4.5 \mathrm{~m} / \mathrm{s}$, and $5 \mathrm{~m} / \mathrm{s}$ are the best. Not only can the values of efficiency provide important information for the power generated, but also give the motivation for developing the simulation code.

\section{CONCLUSIONS}

A small-scale wind turbine generator has been used in this paper to investigate the performance. Simulation by generated a computer program code has been made to compare the results. The results of the present work lead to the following conclusions:

- The performance of three-bladed profile kit wind turbine is better than that calculated for the kit wind turbine with four and six-bladed. There is a significant effect of changing the blade pitch angle on both three and four-bladed rotor, the best results were at $10^{\circ}$ pitch angle.

- The results indicate that for a small horizontal wind turbine with four blades at $5.5 \mathrm{~m} / \mathrm{s}$, the energy production reaches its maximum value (4.1 watts).

- The best overall efficiency obtained for three blades profile at $10^{\circ}$ pitch angle reach about $70 \%$.

- In general, the optimal performance of small horizontal wind turbine occurs for the three blades profile at $10^{\circ}$ and $30^{\circ}$ pitch angle for the velocity range of $(4 \mathrm{~m} / \mathrm{s}$ to $5 \mathrm{~m} / \mathrm{s})$. 


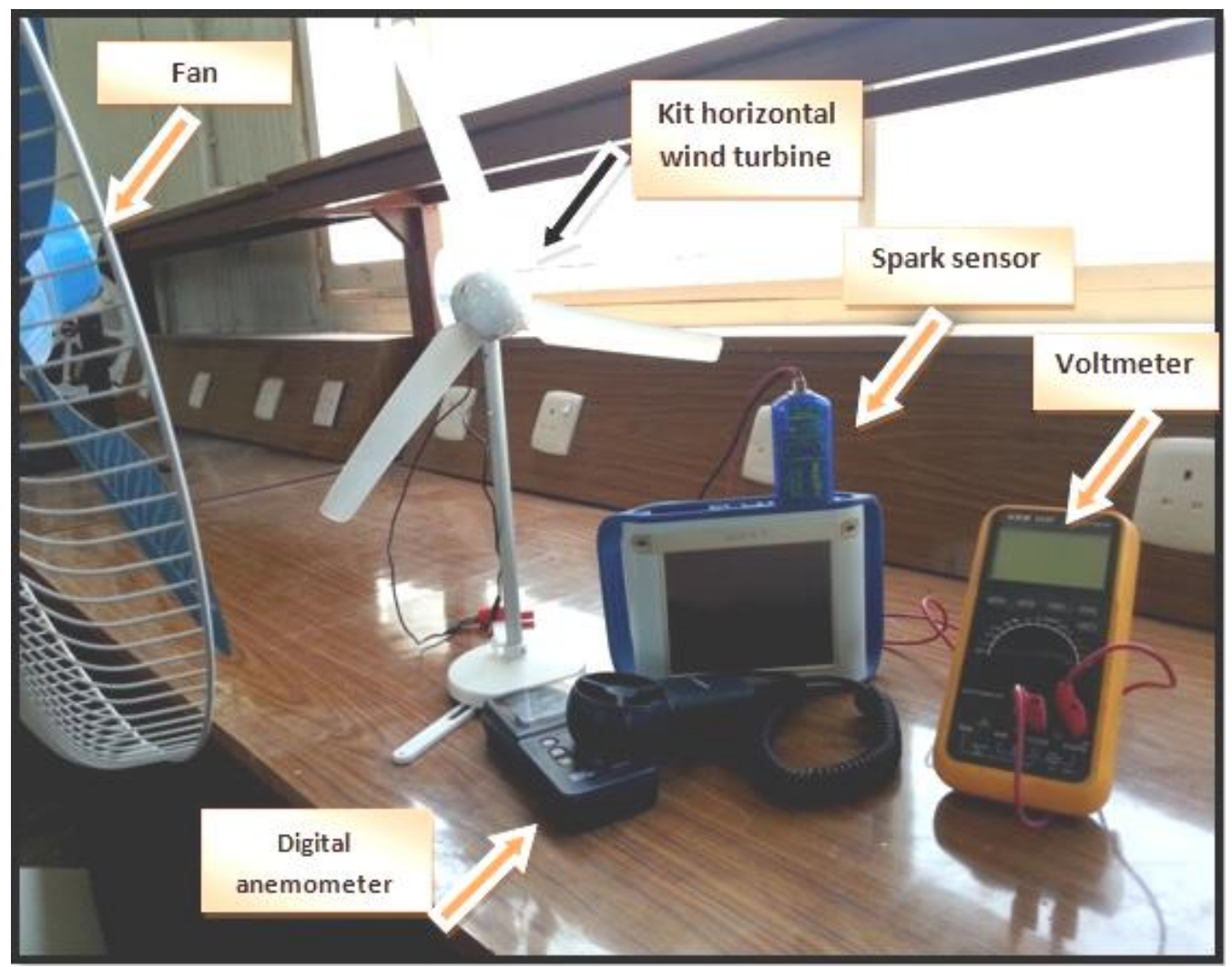

Fig 1: General aspect of the experimental setup.

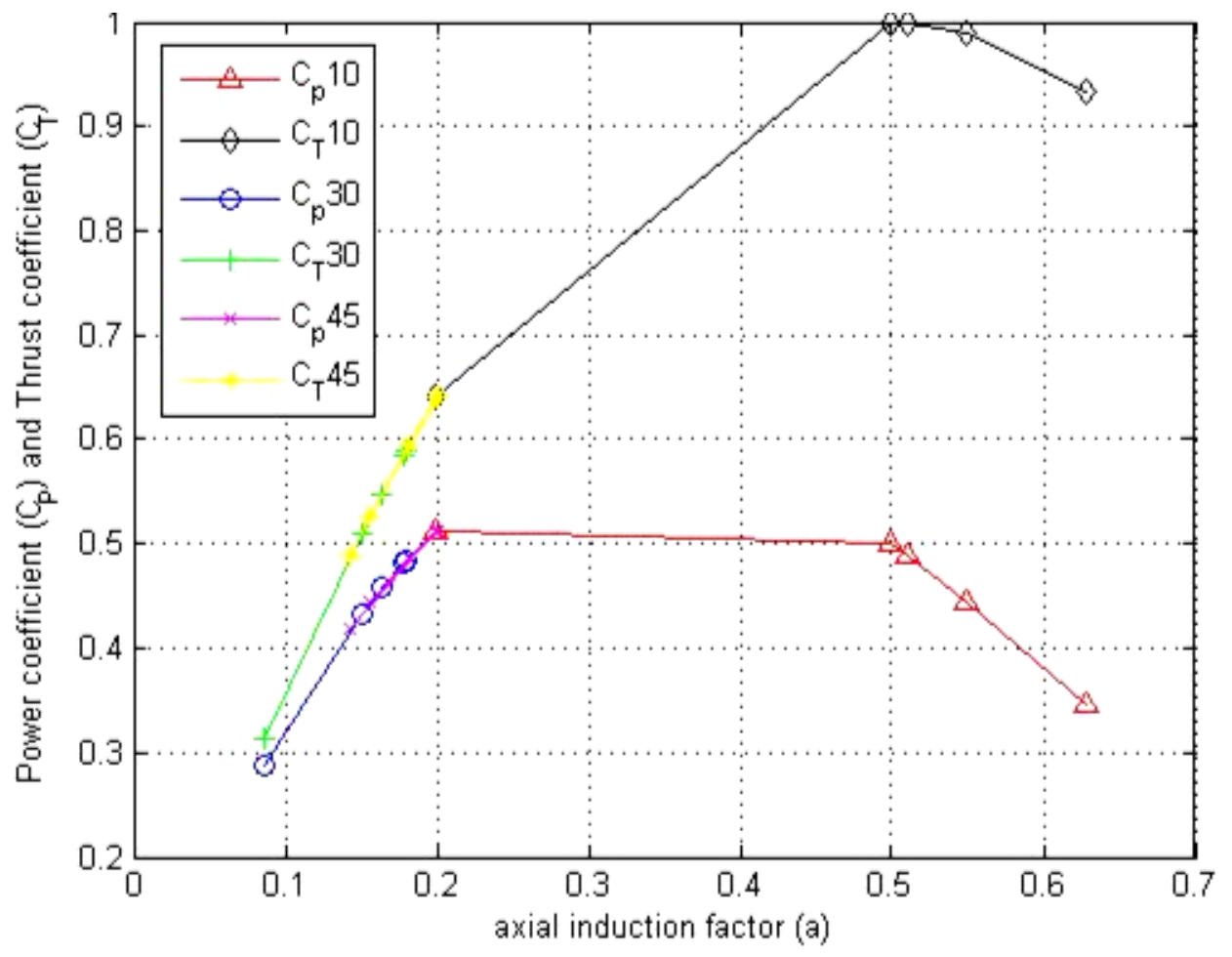

Fig 2: The relationship between $(\mathrm{Cp}, \mathrm{Ct})$ and axial induction factor (a) for three blades and $\left(\mathbf{1 0}^{\circ}, \mathbf{3 0}^{\circ}\right.$, and $\left.45^{\circ}\right)$ pitch angle. 


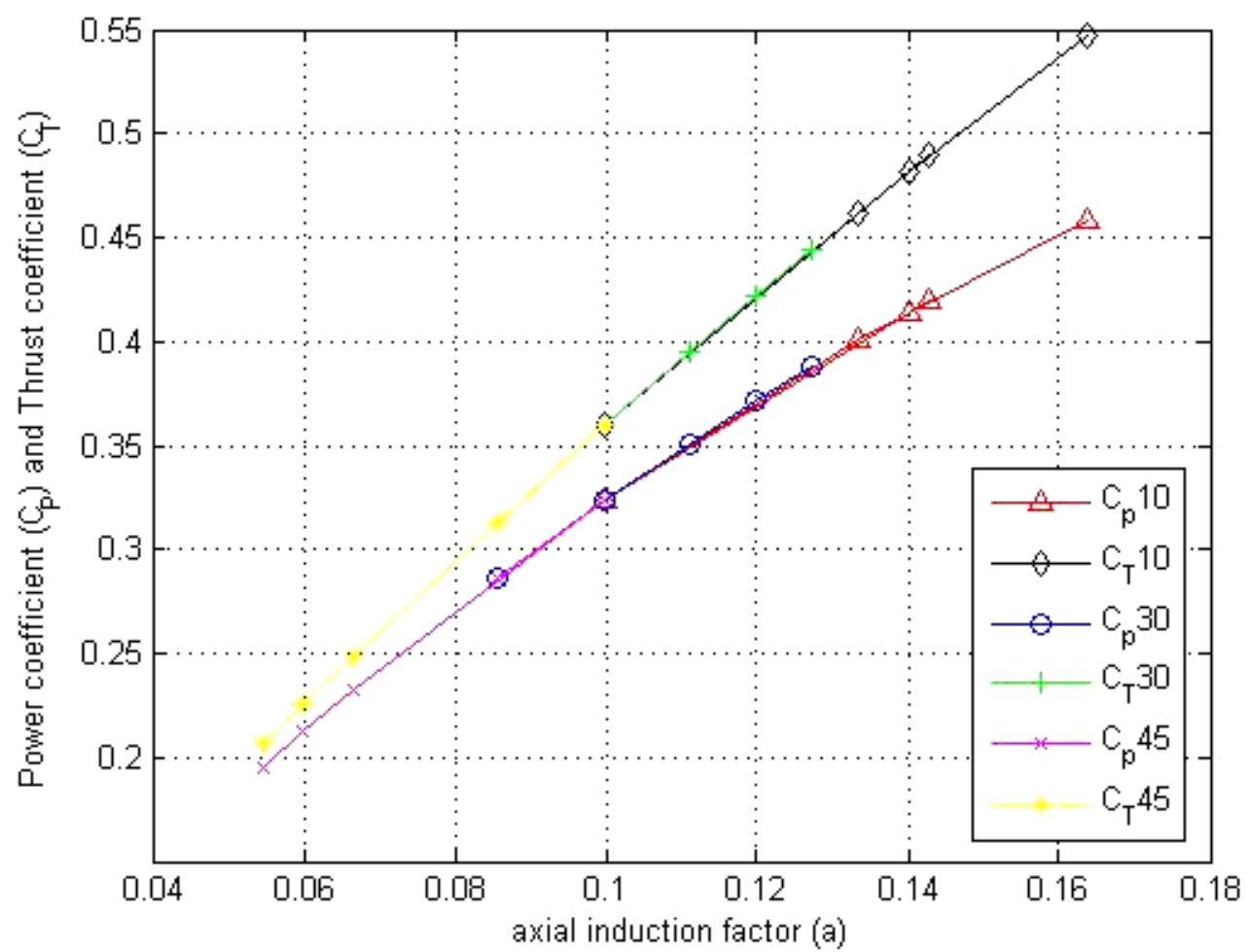

Fig 3: The relationship between $(\mathrm{Cp}, \mathrm{CT})$ and axial induction factor (a) for four blades and $\left(10^{\circ}, 30^{\circ}\right.$, and $\left.45^{\circ}\right)$ pitch angle

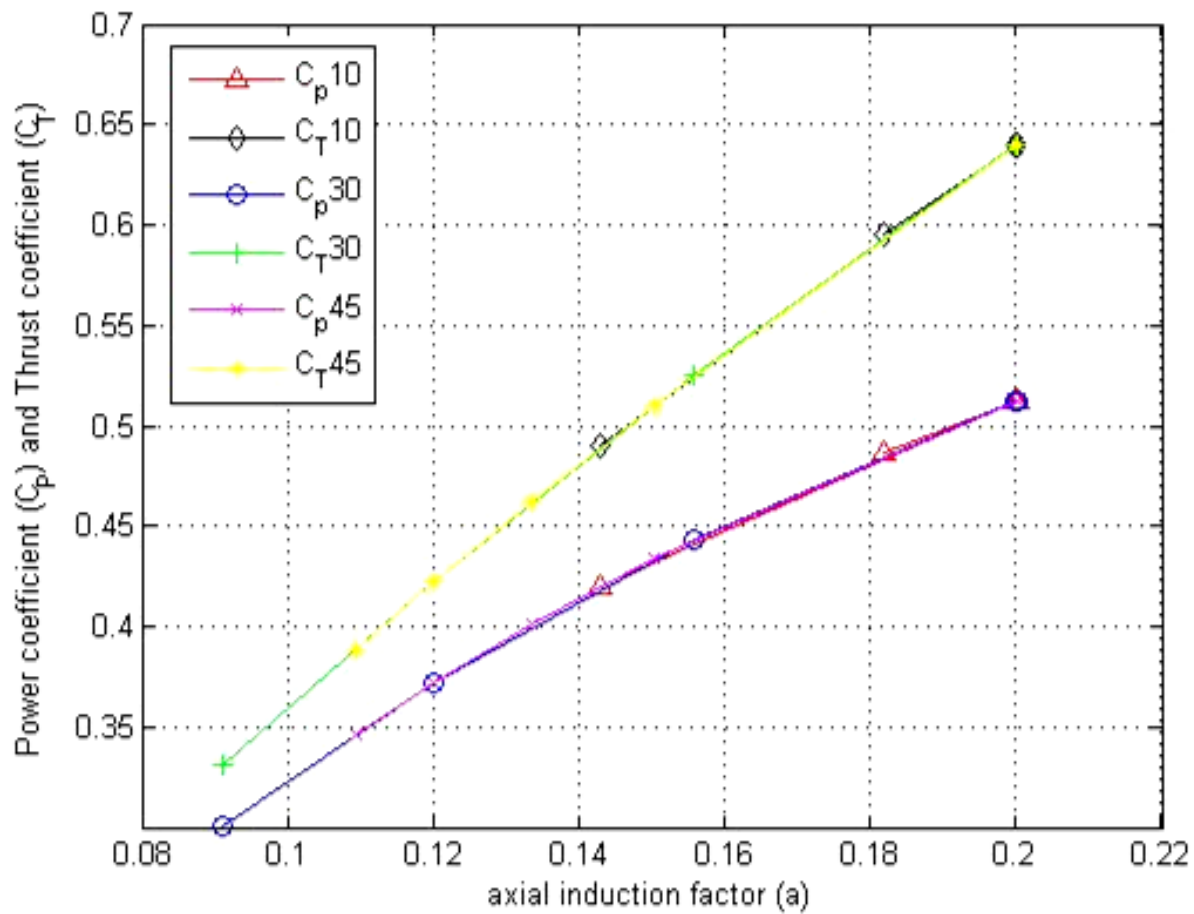

Fig 4: The relationship between $\left(\mathrm{Cp}, \mathrm{C}_{\mathrm{T}}\right)$ and axial induction factor (a) for six blades and $\left(10^{\circ}, 30^{\circ}\right.$, and $\left.45^{\circ}\right)$ pitch angle. 


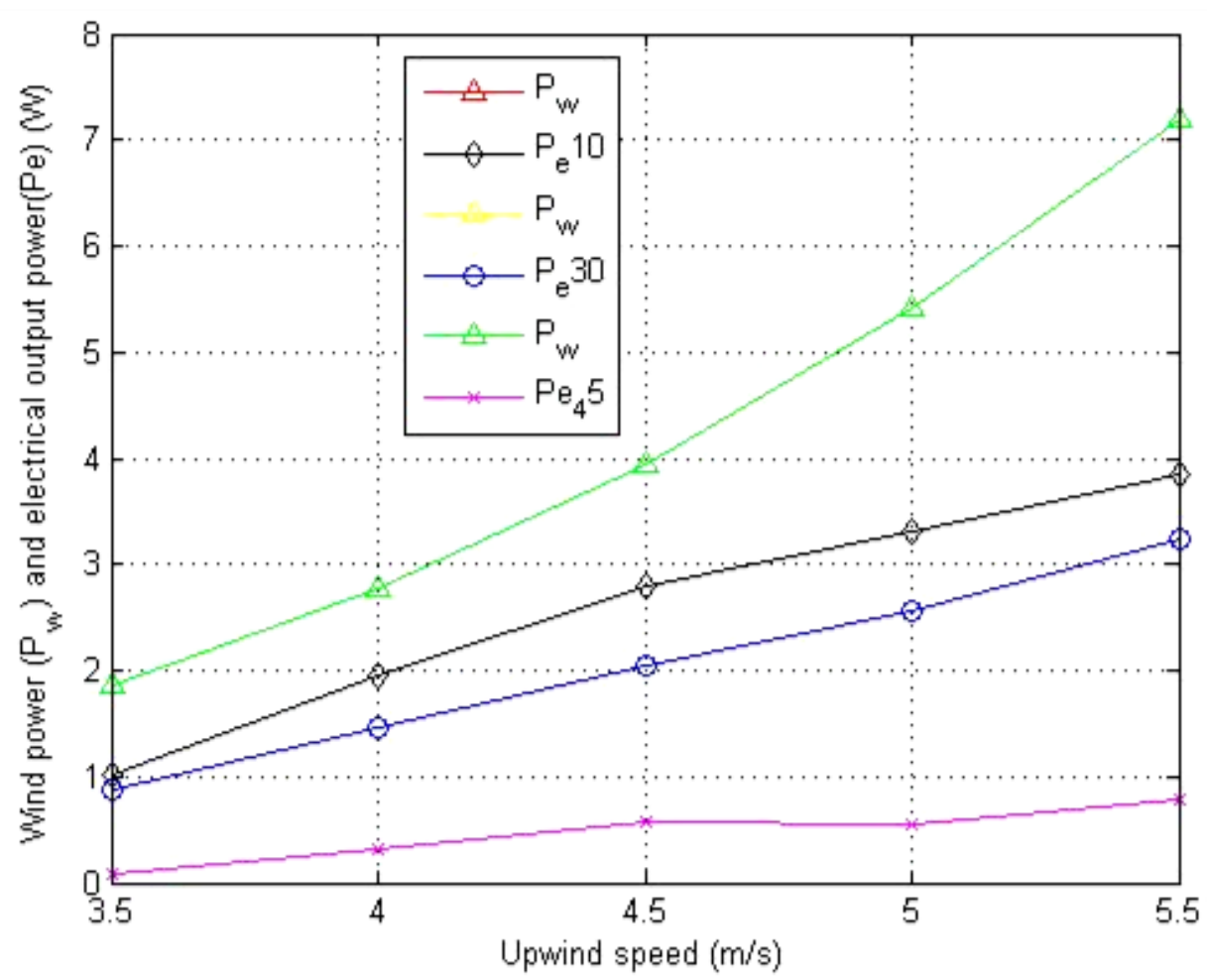

Fig 5: Variation of wind power and output electrical power with upwind speed for three blades and $\left(10^{\circ}, 30^{\circ}\right.$, and $\left.45^{\circ}\right)$ pitch angle.

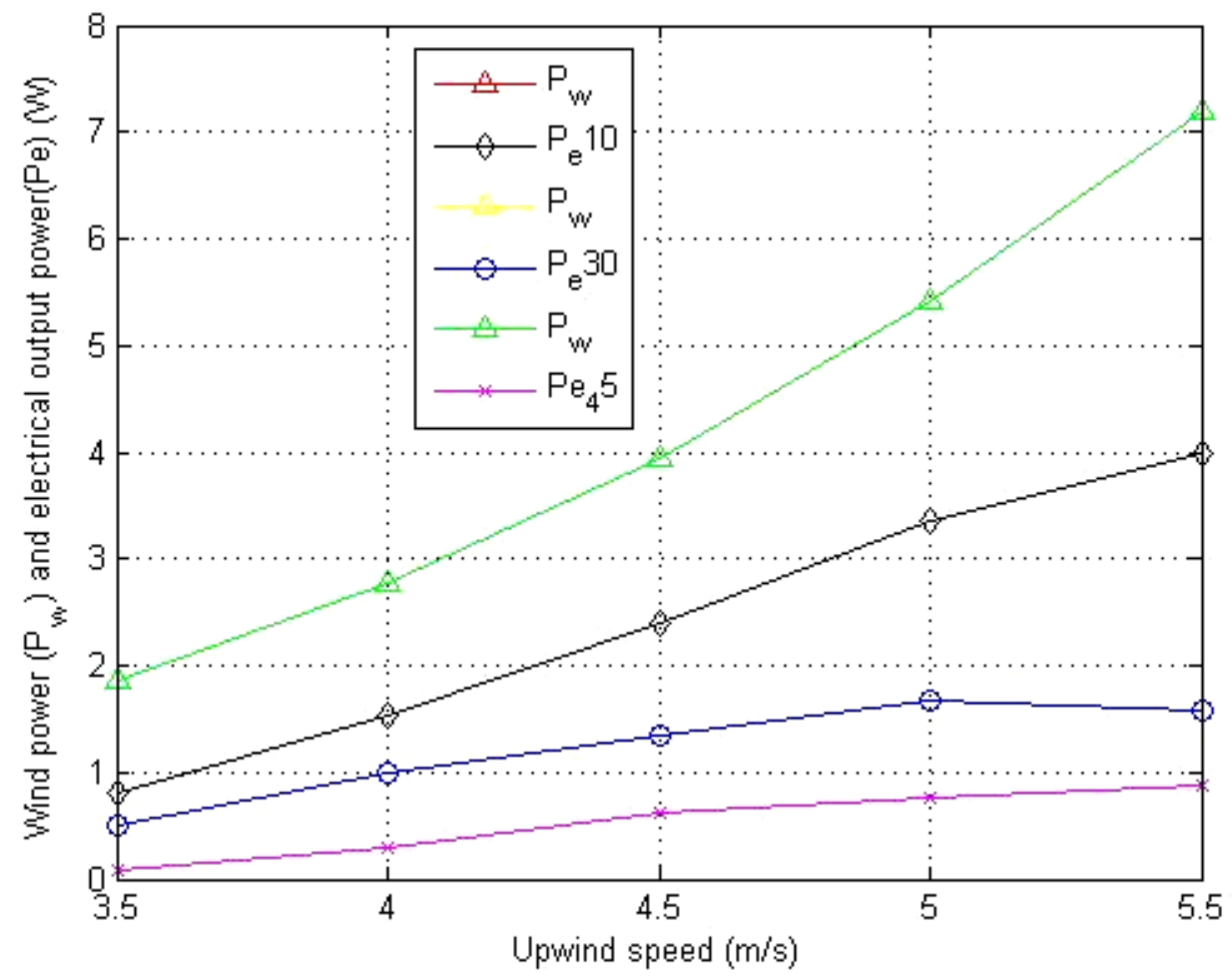

Fig 6: Variation of wind power and output electrical power with upwind speed for four blades and $\left(10^{\circ}, 3^{\circ}\right.$, and $\left._{45}^{\circ}\right)$ pitch angle. 


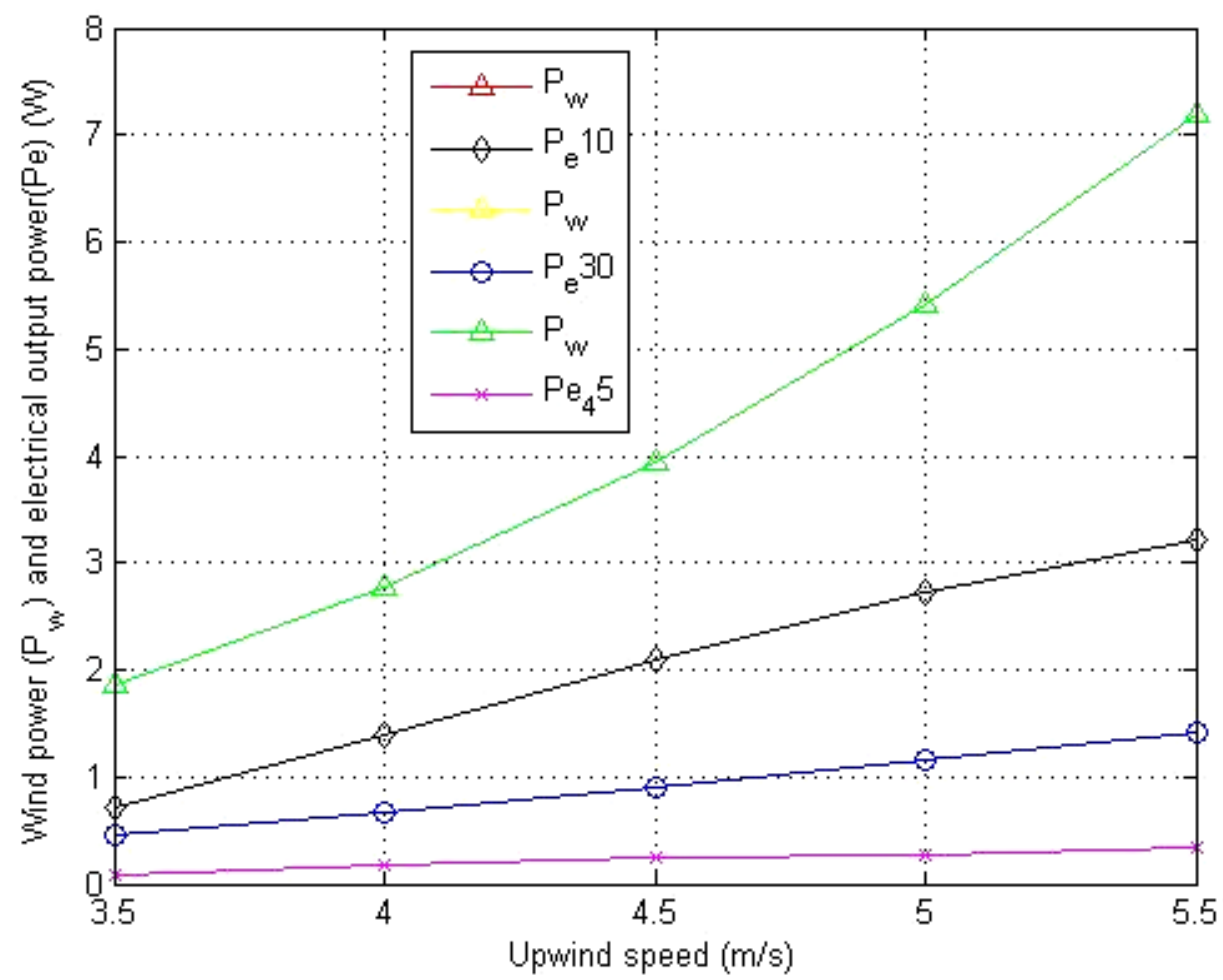

Fig 7: Variation of wind power and output electrical power with upwind speed for six blades and $\left(10^{\circ}, 30^{\circ}\right.$, and $\left.45^{\circ}\right)$ pitch angle.

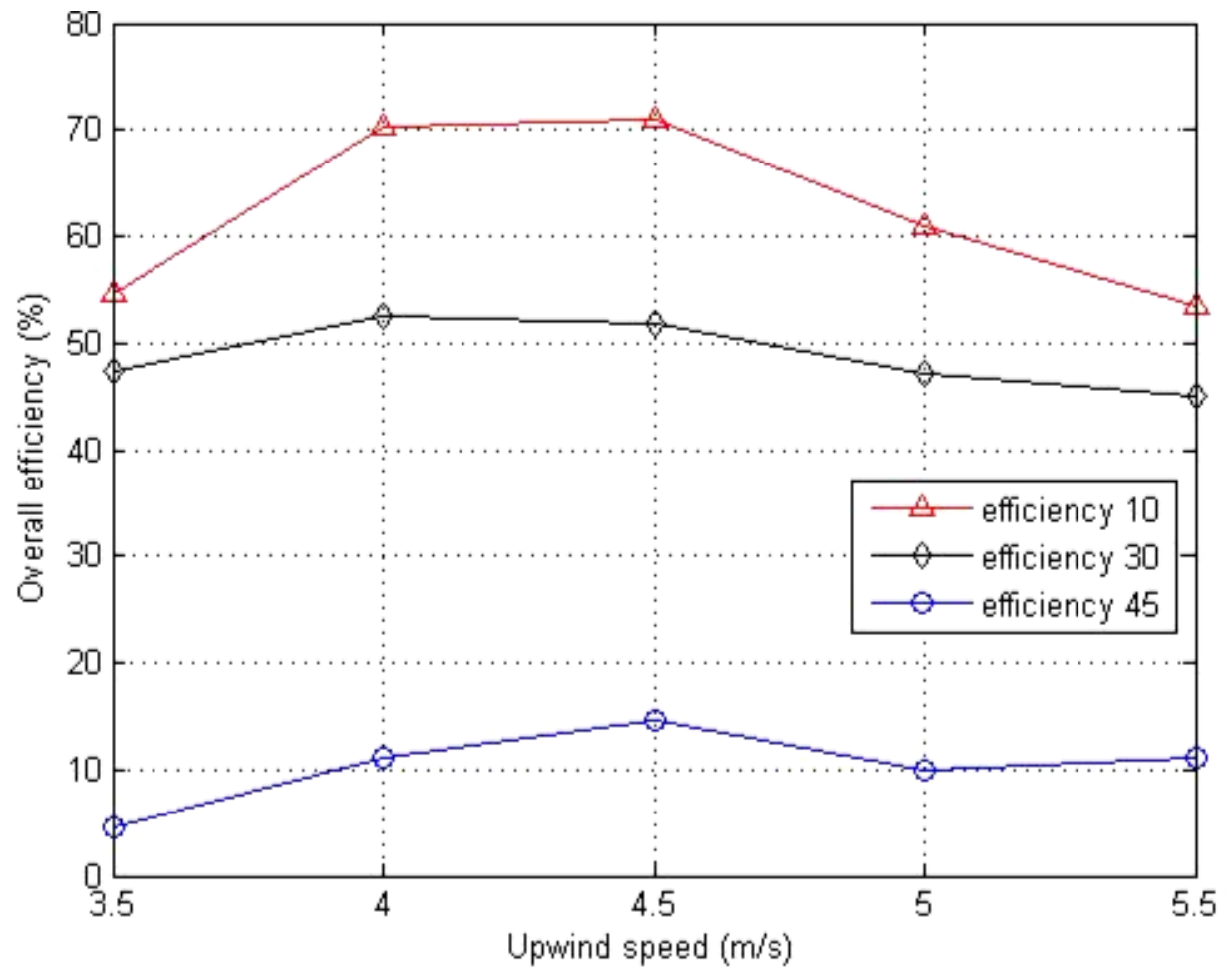

Fig 8: Overall Efficiency of the three-bladed rotor at $\left(10^{\circ}, 30^{\circ}\right.$, and $\left.45^{\circ}\right)$ pitch angle. 


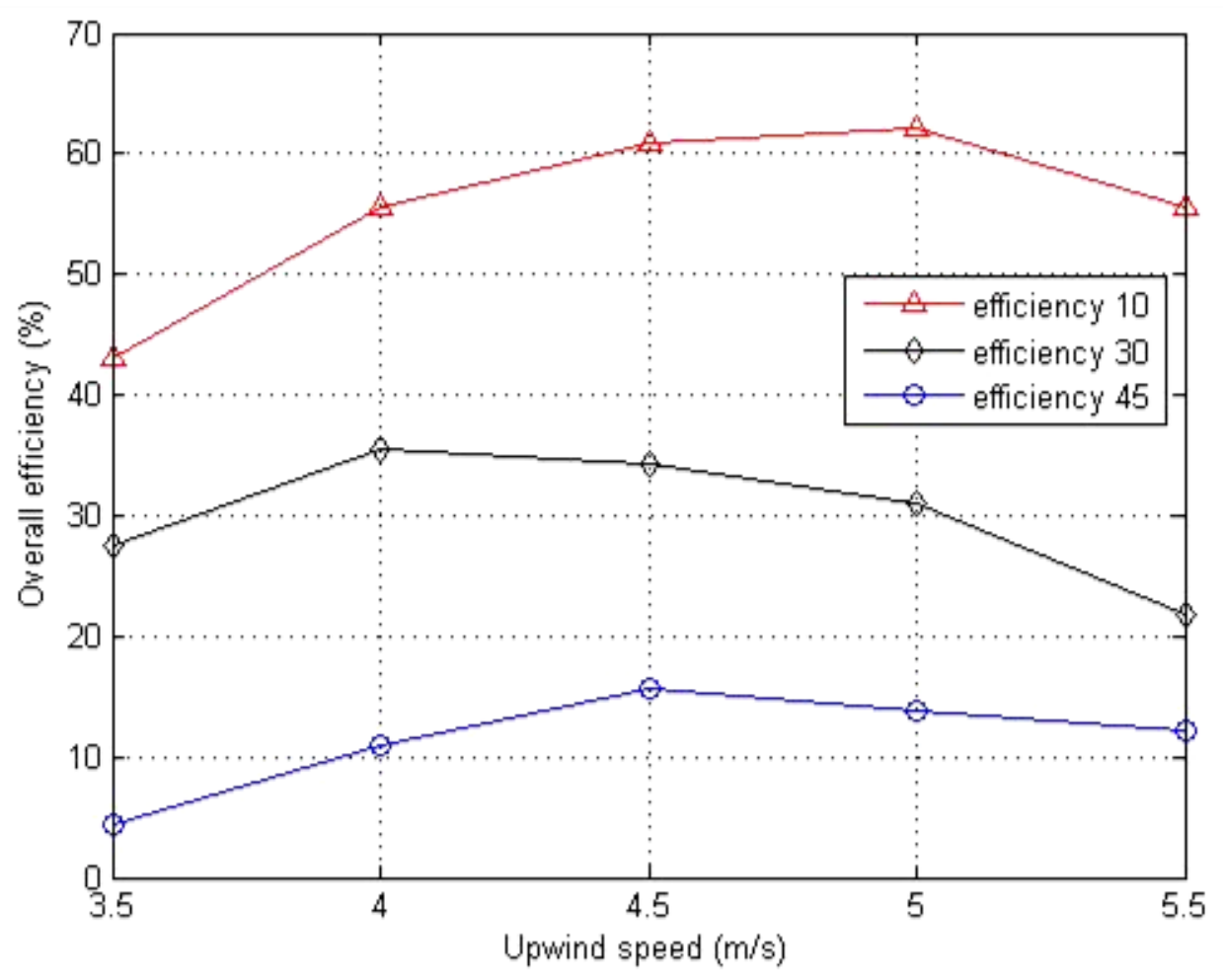

Fig 9: Overall Efficiency of the four-bladed rotor at $\left(10^{\circ}, 30^{\circ}\right.$, and $\left.45^{\circ}\right)$ pitch angle.

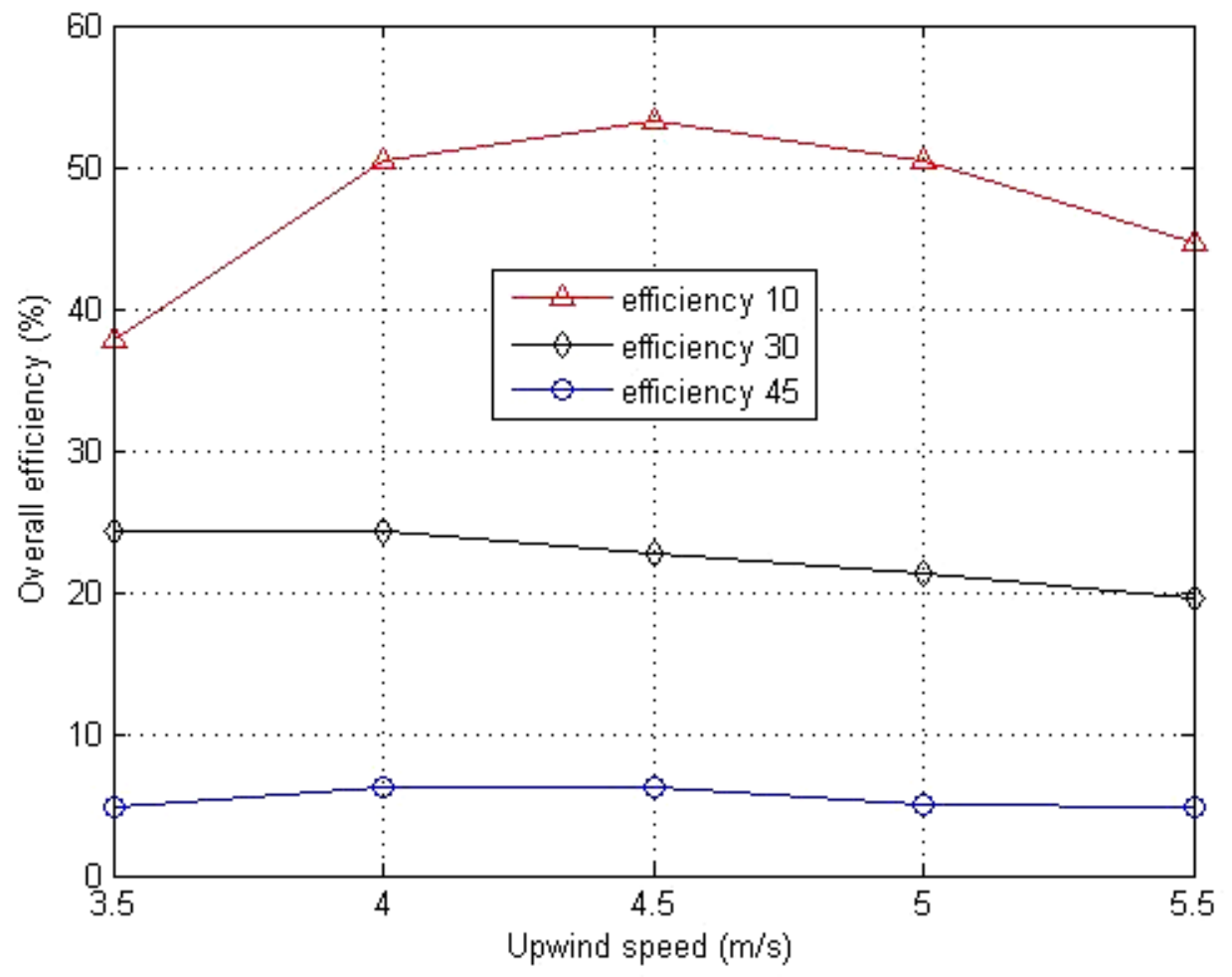

Fig 10: Overall Efficiency of the six-bladed rotor at $\left(10^{\circ}, 30^{\circ}\right.$, and $\left.45^{\circ}\right)$ pitch angle. 


\section{NOMENCLATURES}

$\begin{array}{ll}\text { Symbols } & \text { Description } \\ \mathrm{m} & \text { Air mass }(\mathrm{Kg}) \\ \mathrm{v} & \text { Air velocity }(\mathrm{m} / \mathrm{s}) \\ \mathrm{v}_{1} & \text { Upwind velocity }(\mathrm{m} / \mathrm{s}) \\ \mathrm{v}_{\mathrm{r}} & \text { Rotor velocity }(\mathrm{m} / \mathrm{s}) \\ \dot{\mathrm{m}} & \text { Air mass flow rate }(\mathrm{kg} / \mathrm{s}) \\ \mathrm{A} & \left.\text { Rotor blade area (m }{ }^{2}\right) \\ \mathrm{a} & \text { Axial induction factor } \\ \mathrm{C}_{\mathrm{p}} & \text { Power coefficient } \\ \mathrm{C}_{\mathrm{T}} & \text { Thrust coefficient } \\ \mathrm{P}_{\mathrm{w}} & \text { Power of the wind (watt) } \\ \mathrm{P}_{\mathrm{e}} & \text { Electrical output power(watt) } \\ \mathrm{V} & \text { Voltage (volt) } \\ \mathrm{I} & \text { Current (Ampere) }\end{array}$

Greek symbols

$\begin{array}{ll}\rho & \text { Air density }(1.24 \mathrm{~kg} / \mathrm{m} 3) \\ \eta & \text { Overall efficiency }(\%)\end{array}$

Abbreviations

$\begin{array}{ll}\text { K.E } & \text { Kinetic energy } \\ \text { SHPWT } & \text { Small horizontal portable wind turbine } \\ \text { HAWT } & \text { horizontal axis wind turbine } \\ \text { BEM } & \text { Blade Element Momentum } \\ \text { NACA } & \begin{array}{l}\text { National Advisory Committee for } \\ \text { Aeronautics }\end{array}\end{array}$

\section{REFERENCES}

[1] Dongxiang Jiang, Qian Huang, and Liangyou Hong, 2009. Test System of a Small Wind Turbine under Laboratory Conditions. IEEE 2009 World Non-GridConnected Wind Power and Energy Conference (WNWEC 2009) - Nanjing, China (2009.09.242009.09.26).

[2] A.K. Wright and D.H. Wood, "The starting and low wind speed behavior of a small horizontal axis wind turbine", Journal of Wind Engineering and Industrial Aerodynamics, 92 (2004) 1265-1279.

[3] Ravi Anant Kishore and Shashank Priya, "Design and experimental verification of high-efficiency small wind energy portable turbine (SWEPT)", Journal of Wind Engineering and Industrial Aerodynamics, 118(2013)1219.

[4] Ali M. Rasham, Emad T. Hashim and Shymaa A. Mahdi, "Experimental Investigation for Small Horizontal Portable Wind Turbine of Different Blades Profiles under Laboratory Conditions", International Journal of Computer Applications, Volume 127 - No.14, October 2015.

[5] Saravanan P., Parammasivam K. M., and Selvi Rajan S., "Experimental Investigation on Small Horizontal AxisWind Turbine Rotor Using Winglets", Journal of Applied Science and Engineering, Vol. 16, No. 2, pp. 159_164 (2013).

[6] Nitin Tenguria, N. D. Mittal and Siraj Ahmed, "Evaluation of Performance of Horizontal AxisWind Turbine Blades Based on Optimal Rotor Theory", Journal of Urban and Environmental Engineering, v.5, n.1, p.15-23 (2011).

[7] Ozcan Atlam, "A small-scale education experiment kit with wind generator-PEM electrolyzer system and modeling", Turk J Elec Eng \& Comp Sci, Vol.18, No.4, 2010.

[8] Fei-Bin Hsiao, Chi-Jeng Bai, and Wen-Tong Chong, "The Performance Test of Three Different Horizontal AxisWind Turbine (HAWT) Blade Shapes Using Experimental and Numerical Methods", Energies 2013, 6, 2784-2803.

[9] Abdullateef A. Jadallaha, Dhari Y. Mahmood and Zaid A. Abdulqader, "Optimal Performance of Horizontal Axis Wind Turbine for Low Wind Speed Regime", International Journal of Multidisciplinary and Current Research, Vol.2 (2014) ISSN: 2321-3124.

[10] R. Lanzafame and M. Messina, "Horizontal axis wind turbine working at maximum power coefficient continuously", Renewable Energy 35 (2010) 301-306. 